\title{
In Vitro Dissolution of Aceclofenac Loaded Hydrophilic Polymer Based Matrix Tablets and its Release Mechanism
}

\author{
M. Mesbah Uddin Talukder ${ }^{a *}$, Nadia Ahmed ${ }^{a}$, Tasnuva Haque ${ }^{b}$ and Sadia Afreen Chowdhury \\ ${ }^{a}$ Department of Pharmacy, The University of Asia pacific, Dhaka-1209 and ${ }^{b}$ Department of Pharmacy, \\ Stamford University Bangladesh, Dhaka-1217
}

\begin{abstract}
Hydrophilic polymers are widely used to prepare sustained release matrix tablets. These polymers showed their sustained action by forming a barrier of thick gel layer around the matrix. Here swelling of the polymer and erosion of matrix plays a major role to control the release of the drug. In this present study the swelling and erosion properties of some hydrophilic polymers were correlated to their sustaining and rate controlling behavior. Matrix tablets containing hydroxypropyl methylcellulose (HPMC K100cps), carboxymethyl cellulose (CMC 50,000 cps) and methocel K15M CR polymers were prepared. The powder mixture was evaluated for their flow properties and the prepared tablets for their physical parameters. Swelling and erosion index of the tablets were carried out in $\mathrm{pH} 6.8$ phosphate buffer and dissolution in $0.1 \mathrm{~N} \mathrm{HCl}$ (2 hours) followed by pH 6.8 phosphate buffer (8 hours) using USP apparatus II (paddle method) at 50 r.p.m. HPMC K100 cps was found to be not as rate retarding as the other two. From the all results it was observed that F-6 (containing 43.243\% methocel K15M CR) showed highest swelling and erosion index (740.589\% and $12.017 \%$ respectively), slowest release rate (24.491\% at 8 hours) and highest MDT value (55.401 hours). Finally it can be concluded that increasing the polymer concentration or polymer's viscosity grade, swelling and erosion index increases, release rate decreases and MDT value increases.
\end{abstract}

Key words: Aceclofenac, Matrix tablets, HPMC, CMC, Physical parameters, Release kinetics.

\section{Introduction}

Many strategies are available for the design and development of modified-release drug delivery formulations. The primary purpose of these drug delivery devices is to improve the state of disease management by modifying the pharmacokinetic profiles of therapeutic agents normally administered as conventional tablets or capsules. Conventional oral dosage forms often produce fluctuations of drug plasma level that either exceed safe therapeutic level or quickly fall below the minimum effective level; this effect is usually totally dependent on the particular agent's biologic half-life, frequency of administration, and release rate. It is recognized that many patients can benefit from drugs intended for chronic administration by maintaining plasma levels within a safe and effective range (Theeuwes, 1983). Hydrophilic polymer matrix systems are widely used in oral controlled drug delivery because they make it easier to achieve a desirable drug release profile, they are cost effective, and they have broad US Food and Drug Administration acceptance (Alderman, 1984).The hydrophilic polymer matrix system consists of hydrophilic polymer, drug, and other excipients distributed throughout the matrix. This dynamic system is *Corresponding author: E-mail: mesbah777@yahoo.com dependent on polymer wetting, hydration and dissolution for controlled release of drug. At the same time, other soluble excipients or drug substances will also wet, dissolve and diffuse out of the matrix, whereas insoluble excipients or drug substances will be held in place until the surrounding polymer, excipients, or drug complex erodes or dissolves away (Dow chemical Company 2006). Hydrophilic matrices containing swellable polymers are referred to as hydrogel matrices, swellable controlled release systems or hydrophilic matrix tablets. A number of polymers have been investigated to develop in situ gel-forming systems, due to the ability of these hydrogels to release an entrapped drug in aqueous medium and to regulate the release of such drug by control of swelling and cross-linking (Krowczynsky, 1987). Nonsteroidal anti-inflammatory drugs (NSAIDs) are considered to be the first-line drugs in the symptomatic treatment of rheumatoid arthritis, osteoarthritis and ankylosing spondylitis. Aceclofenac is one of the emerging NSAID molecules for arthritis treatment. It is a newer derivative of diclofenac and has less gastrointestinal complications (Parfitt, 1999). The short biological half-life (about $4 \mathrm{~h}$ ) and dosing frequen- 
cy more than one per day make aceclofenac an ideal candidate for sustained release (Parfitt, 1999). Hydroxypropyl methylcellulose (HPMC), which is commonly used in hydrophilic matrix drug delivery systems, is a mixed alkyl hydroxyalkyl cellulose ether containing methoxyl and hydroxypropyl groups. The hydration rate of HPMC depends on the nature of these substituents, such as the molecular structure and the degree of substitution. Specifically, the hydration rate of HPMC increases with an increase in the hydroxypropyl content. The solubility of HPMC is $\mathrm{pH}$ independent (Alderman, 1984). HPMC has been found to be a very versatile material for the formulation of soluble matrix tablets. It is a widely accepted pharmaceutical excipient and is included in all major compendia. Because HPMC is available in a wide range of molecular weights, effective control of gel viscosity is easily provided (Dow chemical company 2006).

The purpose of the present study was to develop a sustained release dosage form of aceclofenac prepared by using some hydrophilic polymer, such as methocel K15M CR, hydroxyl propylmethyl cellulose (HPMC K100 cps) and carboxy methyl cellulose (CMC 50,000 cps). The release mechanism of drug from the hydrophilic matrix is commonly governed by the swelling of the polymer in contact with water and diffusion of drug from depot which is surrounded by viscous gel barrier in a controlled way. The present study was mainly focused on the actual release pattern of the drug from the matrix, to find out whether it relates with the theoretical concept.

\section{Materials and Methods}

Aceclofenac, CMC 50,000 cps and HPMC K100 cps were purchased from TecnoPharma (Bangladesh), methocel
K15M CR was a gift sample from Incepta Pharmaceuticals Ltd. (Bangladesh), kollidone K30 (Albright and Wilson Ltd.), Pre gelatinized starch (Starch 1500), magnesium stearate and talc were from Chaina. Among the instruments, electronic balance (Shimadzu, Japan), hydraulic press (Perkin-Elmer, USA), dissolution apparatus (Veego, India), uv-visible spectrophotometer (Shimadzu, Japan), pH meter (Eutech instrument, Singapore), hardness tester (Veego, India), friabilator (Veego, India), digital vernier caliper (SDK, China), sonicator (Hwasin Technology, Korea) and densitometer (Veego, India) were used.

\section{Preparation of matrix tablets}

According to the formulation given in Table I, accurately weighted ingredients (except magnesium stearate and talc) were taken in a mortar and blended well with pestle for about 5 minutes. Then magnesium stearate and talc were added and mixed with the previous mixture. Particular attention has been given to ensure through mixing and phase homogenization. The appropriate amounts of the mixture were accurately weighted in an electronic balance for the preparation of each tablet. Now, this mixture was taken in a Perkin-Elmer hydraulic press equipped with $13 \mathrm{~mm}$ diameter flat faced punch and die set ( punch and die were previously lubricated with a $1 \%$ dispersion of magnesium stearate in ethanol) and using 5 tonnes pressure it was compacted and it was left in this compact state for about 5 minutes. Finally the upper punch was withdrawn and tablet was ejected. Thus each tablet of $13 \mathrm{~mm}$ diameter was prepared.

Table I. Formulation of different hydrophilic polymer based matrix tablets.

\begin{tabular}{l|c|c|c|c|c|c|c|c|c}
\hline Formula & $\begin{array}{c}\text { Drug } \\
\text { (Aceclofenac) }\end{array}$ & $\begin{array}{c}\text { HPMC } \\
\text { K 100 } \\
\text { cps }\end{array}$ & $\begin{array}{c}\text { CMC } \\
50,000 \\
\text { cps }\end{array}$ & $\begin{array}{c}\text { Methocel } \\
\text { K15M } \\
\text { CR }\end{array}$ & $\begin{array}{c}\text { Kollidon } \\
\text { K30 }\end{array}$ & $\begin{array}{c}\text { Starch } \\
1500\end{array}$ & $\begin{array}{c}\text { Mg- } \\
\text { Stearate }\end{array}$ & Talc & TOTAL \\
\hline 1 & 100 & 80 & - & - & 20 & 160 & 5 & 5 & 370 \\
2 & 100 & 160 & - & - & 20 & 80 & 5 & 5 & 370 \\
3 & 100 & - & 80 & - & 20 & 160 & 5 & 5 & 370 \\
4 & 100 & - & 160 & - & 20 & 80 & 5 & 5 & 370 \\
5 & 100 & - & - & 80 & 20 & 160 & 5 & 5 & 370 \\
6 & 100 & - & - & 160 & 20 & 80 & 5 & 5 & 370 \\
7 & 100 & - & 80 & 80 & 20 & 80 & 5 & 5 & 370 \\
8 & 100 & - & 50 & 110 & 20 & 80 & 5 & 5 & 370 \\
9 & 100 & - & 110 & 50 & 20 & 80 & 5 & 5 & 370 \\
\hline
\end{tabular}




\section{Evaluation of flow property of the powder mix and phys- ical parameters of the prepared tablets}

The powder mixture (without adding magnesium stearate and talc) was tested for their flow property. Bulk density, tapped density, Carr's compressibility index (Wells et al., 1998), Hausner ratio ((Wells et al., 1998) and angle of repose (Raghuram et al., 2003) were determined. Tablets were evaluated for their diameter, thickness, weight, hardness, axial tensile strength (Fell et al., 1968), radial tensile strength (Fell et al., 1968)) and friability (Ruiz et al., 2006).

\section{In vitro dissolution study}

In vitro drug release studies from the prepared matrix tablets were conducted for a period of 10 hours using an USP dissolution apparatus II (perfect sink conditions) set at 50 r.p.m. and a temperature of $37 \pm 0.5^{\circ} \mathrm{C}$. The tablets were placed in $750 \mathrm{ml}$ of a $0.1 \mathrm{~N} \mathrm{HCl}$ solution at $\mathrm{pH} 1.5$ for 2 hours. After 2 hours, the acid stage was changed into buffer stage followed by addition of $250 \mathrm{ml} 0.2 \mathrm{M}$ tribasic sodium phosphate into $750 \mathrm{ml}$ of $0.1 \mathrm{~N} \mathrm{HCl}$ to raise the $\mathrm{pH}$ up to 6.8. The study continued for a further 8 hours. At specified intervals (2 hours) $10 \mathrm{ml}$ samples were withdrawn from the dissolution medium and replaced with fresh medium to keep the volume constant. After appropriate dilution, the samples were filtered through a Whatmaan filter paper $(0.45 \mu \mathrm{m})$ and diluted to a suitable concentration with required media. The sample solution was analyzed at $276 \mathrm{~nm}$ for the presence of aceclofenac, using UV Spectrophotometer. The amount of drug released was calculated using the calibration curves constructed in the two dissolution media.

\section{Release kinetics}

The suitability of several equations that are reported in the literature to identify the mechanisms for the release of NAP from SR portion was tested with respect to the release data. The data were evaluated according to the following equations:

Zero-order model (Donbrow et al., 1980):

$\mathrm{M}_{\mathrm{t}}=\mathrm{M}_{0}+\mathrm{K}_{0} \mathrm{t}$

Higuchi model (Higuchi, 1961; Higuchi, 1963):

$\mathrm{M}_{\mathrm{t}}=\mathrm{M}_{0}+\mathrm{K}_{\mathrm{H}} \mathrm{t}^{0.5}$

Korsmeyer-Peppas model (Korsmeyer et al., 1983; Peppas, 1985):

$\mathrm{M}_{\mathrm{t}}=\mathrm{M}_{0}+\mathrm{K} \mathrm{t}^{\mathrm{n}}$
Where Mt is the amount of drug dissolved in time $t, \mathrm{M}_{0}$ is the initial amount of drug, $\mathrm{K}_{0}$ is the zero-order release constant, $\mathrm{K}_{\mathrm{H}}$ is the Higuchi rate constant, $\mathrm{K}$ is a release constant and $\mathrm{n}$ is the release exponent that characterizes the mechanism of drug release.

The magnitude of the exponent $n$ indicates that the release mechanism is Fickian diffusion, case II transport or anomalous transport. In the present study (cylindrical shape) the limits considered were $n=0.45$ (indicates a classical Fickian diffusion-controlled drug release) and $n=0.89$ (indicates a case II relaxational release transport: polymer relaxation controls drug delivery). Values of $\mathrm{n}$ between 0.45 and 0.89 can be regarded as indicators of both phenomena (transport corresponding to coupled drug diffusion in the hydrated matrix and polymer relaxation), commonly called anomalous non-Fickian transport. Values of $\mathrm{n}$ greater than 0.89 indicates super case II transport, in which a pronounced acceleration in solute release by a film occurs toward the latter stages of release experiments, resulting in a more rapid relaxation-controlled transport (Jacques et al., 1974).

Due to the differences in drug release kinetics, the constant $\mathrm{k}$, though one of the measures of release rate, should not be used for comparison. Therefore, to characterize the drug release rates in different experimental conditions, mean dissolution time (MDT) was calculated from dissolution according to Mockel and Lippold (Mockel et al., 1993) using the following equation:

$\operatorname{MDT}=n \times\left(\mathrm{K}^{1 / \mathrm{n}}\right) /(\mathrm{n}+1) \ldots \ldots \ldots \ldots(4)$

Where $\mathrm{n}$ is the release exponent and $\mathrm{K}$ is the kinetic constant calculated from Equation 3.

The similarity factor was used to compare the difference of dissolution profiles of the test matrix tablets is given below:

$f_{2}=50 \log \left\{\left[1+\frac{1}{n} \sum_{t=1}^{n}\left(R_{t}-T_{t}\right)^{2}\right]^{-0.5} \times 100\right\}$

where $R_{t}$ and $T_{t}$ are the percentage of drug dissolved at each time point for the test and reference products, respectively and $n$ is the number of dissolution samples taken The US Food and Drug Administration and the European Agency for the Evaluation of Medicinal Products have suggested that 2 dissolution profiles can be considered similar if $f_{2}$ is between 50 and 100 (CDER, 2006; EMEA, 2006). 


\section{Determination of Swelling: Eroding Behavior}

The swelling-eroding behavior of matrix tablets was determined by the method reported by Al-Taani et al., 2003. Matrix tablet was introduced into the dissolution apparatus under the standard set of conditions as specified for determination of in vitro drug release. The tablets were removed using a small basket and swollen weight of each tablet was determined. To determine matrix erosion, swollen tablets were placed in a vacuum oven at $40^{\circ} \mathrm{C}$ and after 48 hours tablets were removed and weighed. Swelling (\%) and erosion (\%) was calculated according to the following formula, where $\mathrm{S}$ is the weight of the matrix after swelling; $\mathrm{R}$ is the weight of the eroded matrix; and $\mathrm{T}$ is the initial weight of the matrix

$\%$ Swelling $=\mathrm{S} / \mathrm{R} \times 100$

$\%$ Erosion $=(\mathrm{T}-\mathrm{R}) / \mathrm{T} \times 100$

\section{Statistical analysis}

The dissolution data were treated using one way repeated measure ANOVA (SPSS software, version 16.0).

\section{Results and Discussion}

The granules of different formulations were evaluated for angle of repose, tapped density (TD), poured density (PD), Carr's index and Hausner ratio (HR) (Table II). The results of angle of repose and Carr's index ranged from 30.890 to 34.890 and 19.231 to 26.485 respectively. A good correlation observed between Carr's compressibility index and angle of repose in case of nine formulations (Fig. 1). Hausner ratios were within the range of 1.238 to 1.360 . If the value of angle of repose present in the range of 30 -34, it indicates the flow property of the powder mix is passable (the flow can be improved by adding glident) (Wells et al., 1998). If the value of Carr's compressibility index is within the range of 18-21, it indicates the flow might be fair to passable and if it is within 23 to 25, it indicates poor flow (Wells et al., 1998). From the Carr's compressibility index given in table II, it is observed that F-3 and F-5 showed fair to passable flow and the rest of the formulations gave poor flow, which can be improved by using glident. If the Hausner ratio is less than 1.25 , it indicates good flow and if it is within 1.25 to 1.50 , it gives poor flow which also can be improved using glident. Due to the above reason, magnesium stearate and talc were used in all formulation to improve their flow property.

The tablets were prepared according to the formulation given in table I by direct compression method. The prepared tablets were evaluated for their diameter, thickness, uniformity of weight, friability, axial tensile strength and radial tensile strength (Table III). The average weight, average diameter and average thickness ranged from $369.520 \mathrm{mg}$ to 371.500 $\mathrm{mg}, 13.090 \mathrm{~mm}$ to $13.150 \mathrm{~mm}$ and $2.220 \mathrm{~mm}$ to $2.660 \mathrm{~mm}$ respectively. The friability value lied within $0.140 \%$ to $0.880 \%$. From the values of axial and radial tensile strength, it can be stated that F-3 and F-6 showed highest radial (0.100 and $0.183 \mathrm{~kg} / \mathrm{mm}^{2}$ respectively) as well as axial tensile strength $\left(0.038\right.$ and $\left.0.074 \mathrm{~kg} / \mathrm{mm}^{2}\right)$. The correlation between axial and radial tensile strength was shown in Fig. 2.

Swelling studies were carried out in order to investigate whether the extent of swelling varied for the different formulations. When a matrix comes into contact with an aqueous solution, wetting occurs at the surface and then progressing into the matrix through microscopic pores. The nature of the polymer plays an important role in this swelling process of the matrix tablets. The presence of water in the polymer

Table II. Flow properties of powder mix (without adding glident) of different formulations

\begin{tabular}{c|c|c|c|c|c}
\hline Formula & $\begin{array}{c}\text { Bulk density } \\
\left(\mathrm{gm} / \mathrm{cm}^{3}\right)\end{array}$ & $\begin{array}{c}\text { Tapped desity } \\
\left(\mathrm{gm} / \mathrm{cm}^{3}\right)\end{array}$ & $\begin{array}{c}\text { Compressibility index } \\
\text { (in percent) }\end{array}$ & $\begin{array}{c}\text { Hausner ratio } \\
\text { Angle of repose } \\
(\mathrm{Degree})\end{array}$ \\
\hline F-1 & 0.500 & 0.670 & 25.373 & 1.340 & 34.890 \\
F-2 & 0.444 & 0.591 & 24.758 & 1.329 & 33.560 \\
F-3 & 0.590 & 0.735 & 19.672 & 1.245 & 30.890 \\
F-4 & 0.552 & 0.750 & 26.485 & 1.238 & 34.250 \\
F-5 & 0.538 & 0.667 & 19.231 & 1.313 & 30.890 \\
F-6 & 0.500 & 0.656 & 23.810 & 1.317 & 31.420 \\
F-7 & 0.519 & 0.683 & 24.074 & 1.342 & 33.890 \\
F-8 & 0.520 & 0.698 & 25.488 & 1.293 & 34.120 \\
F-9 & 0.533 & 0.690 & 22.671 & 32.560 \\
\hline
\end{tabular}




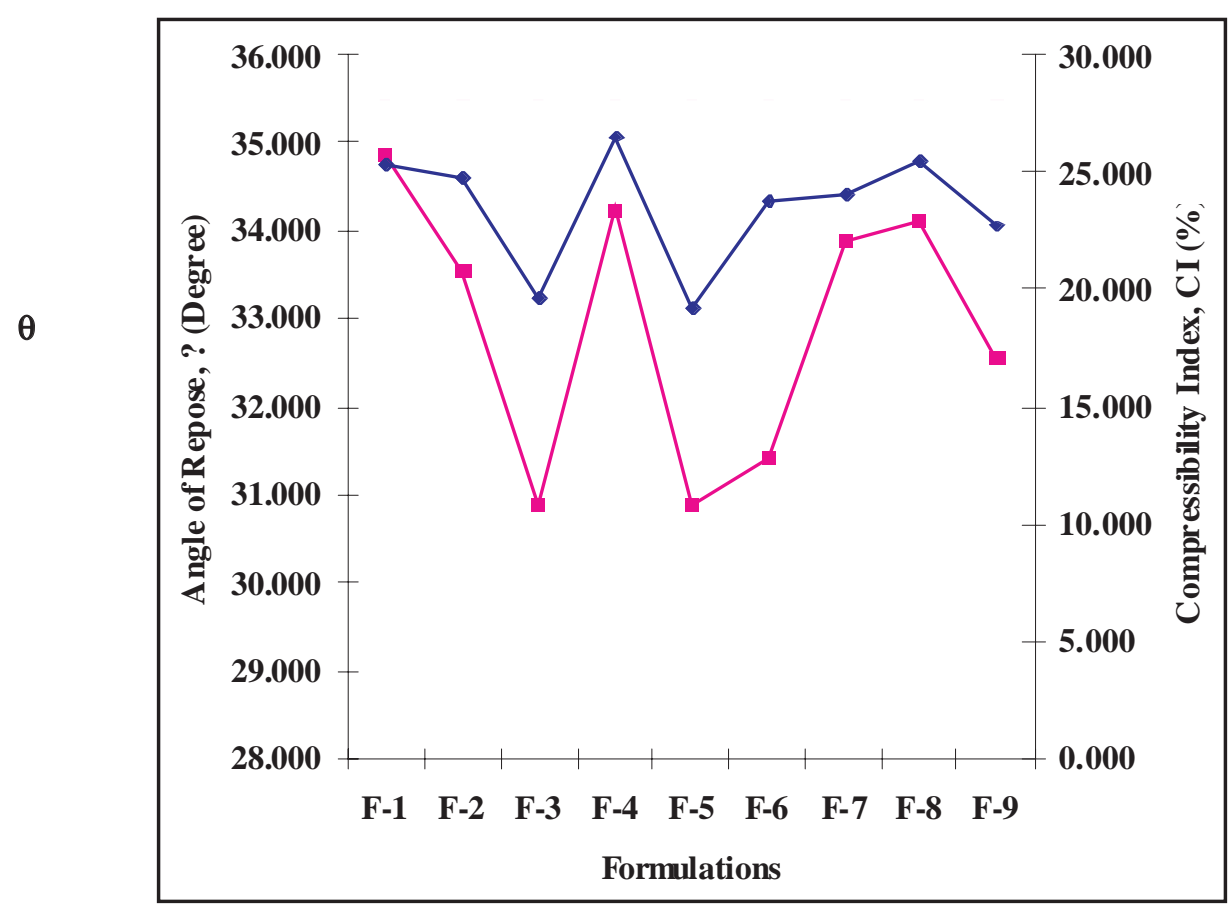

Fig. 1. Relationship between Carr's Compressibility Index, CI (\%) and Angle of Repose, $\theta$ (degrees) of different formulations of hydrophilic polymer based matrix tablets

Table III. Physical parameters of different formulations of hydrophilic polymer based matrix tablets*

\begin{tabular}{c|c|c|c|c|c|c}
\hline Formula & $\begin{array}{c}\text { Avg. wt. } \\
(\mathrm{mg})\end{array}$ & $\begin{array}{c}\text { Avg. diameter } \\
(\mathrm{mm})\end{array}$ & $\begin{array}{c}\text { Avg. thickness } \\
(\mathrm{mm})\end{array}$ & $\begin{array}{c}\text { Friability } \\
\text { (in percent) }\end{array}$ & $\begin{array}{c}\text { Axial tensile } \\
\text { strength }\left(\mathrm{kg} / \mathrm{mm}^{2}\right)\end{array}$ & $\begin{array}{c}\text { Radial tensile } \\
\text { Strength }\left(\mathrm{kg} / \mathrm{mm}^{2}\right)\end{array}$ \\
\hline F-1 & 371.500 & 13.090 & 2.460 & 0.850 & 0.010 & 0.028 \\
F-2 & 370.250 & 13.140 & 2.420 & 0.880 & 0.018 & 0.048 \\
F-3 & 371.060 & 13.140 & 2.520 & 0.140 & 0.038 & 0.100 \\
F-4 & 369.880 & 13.150 & 2.220 & 0.260 & 0.015 & 0.044 \\
F-5 & 369.520 & 13.100 & 2.480 & 0.250 & 0.015 & 0.039 \\
F-6 & 370.450 & 13.100 & 2.660 & 0.150 & 0.074 & 0.183 \\
F-7 & 370.520 & 13.110 & 2.440 & 0.250 & 0.001 & 0.004 \\
F-8 & 369.890 & 13.110 & 2.440 & 0.260 & 0.024 & 0.064 \\
F-9 & 370.450 & 13.120 & 2.360 & 0.250 & 0.013 & 0.037 \\
\hline
\end{tabular}

* Mean value of three tablets

causes a certain amount of stress, resulting in hydration of the polymer, which starts to swell yielding a gelatinous viscous layer (Korsmeyer et al., 1983). Matrix erosion and dissolution systems can provide means of overcoming the wellknown advantage of a purely diffusion control system. Synchronization between erosion and diffusion fronts has been identified to produce zero order drug release (Durig et al., 1999). In order to understand the influence of the hydrophilic polymer system on drug release, swelling and erosion study on matrices containing the polymers only was evaluated. Since both swelling and erosion occurred simultaneously in the matrix, zero order release can be obtained in such types of matrices (Padmalatha et al., 1989). This behavior is responsible for maintaining zero order release in which the increase in diffusion path length due to swelling is balanced with the decrease in the diffusion path length due to matrix erosion. Overall a constant diffusion path length is maintained. From the swelling and erosion study, it was observed that swelling and erosion took place simultaneously. 


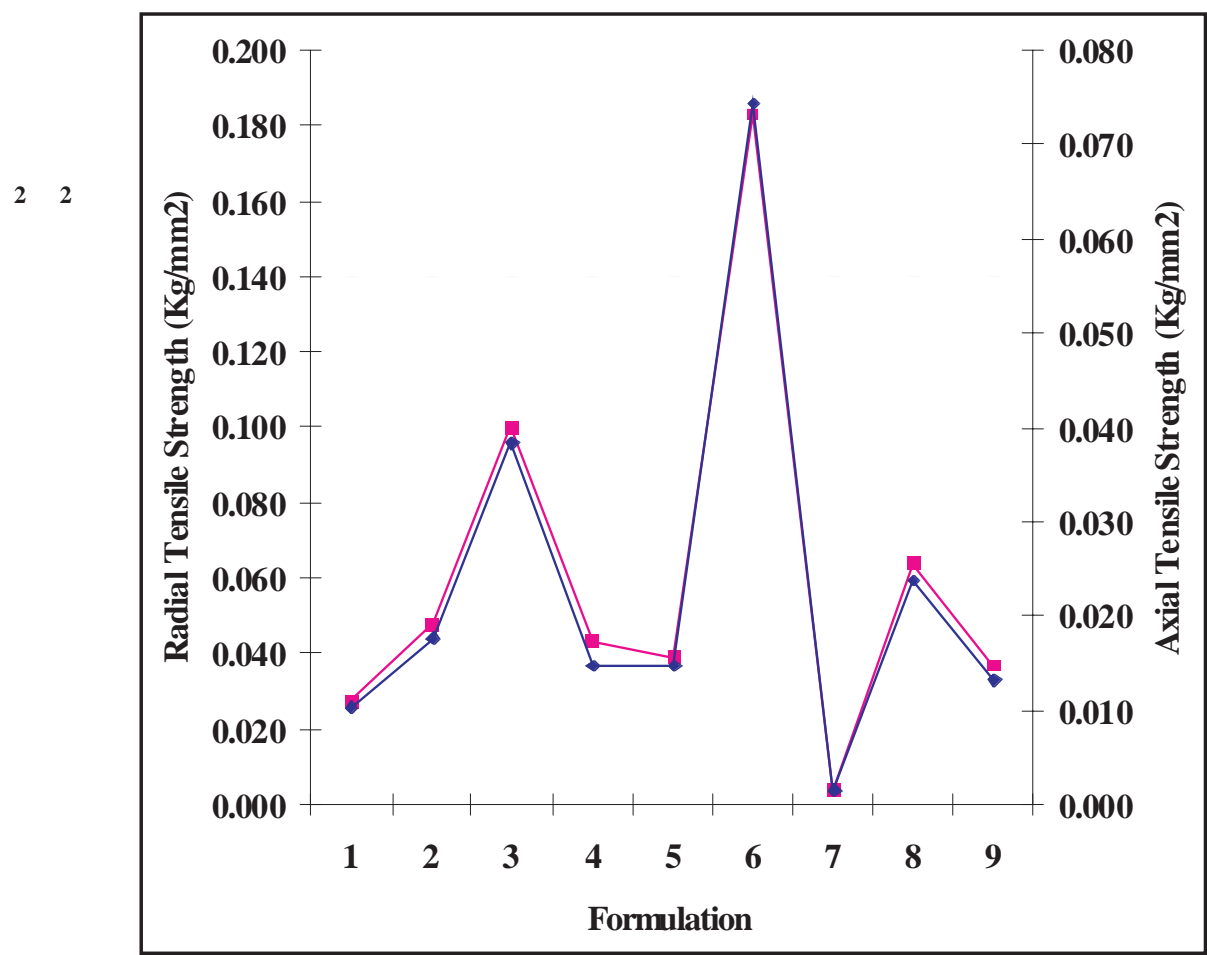

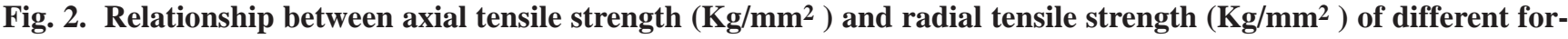
mulations of hydrophilic polymer based matrix tablets

Upon placement in an aqueous medium, several processes occur simultaneously and influence drug release, namely, solvent uptake, swelling of the matrix, dissolution of the drug, and hydration and dissolution of the polymer chain due to chain disentanglement (Reynolds et al., 1999). Tablets of nine formulations were tested for swelling and erosion study. F-1 and F-2 showed no swelling of the matrix rather rapid disintegration. That's why figure 3 was constructed to represent the swelling and erosion index of F-3 to F-9. All of the seven formulations were found to be swelled up to 7 hours.

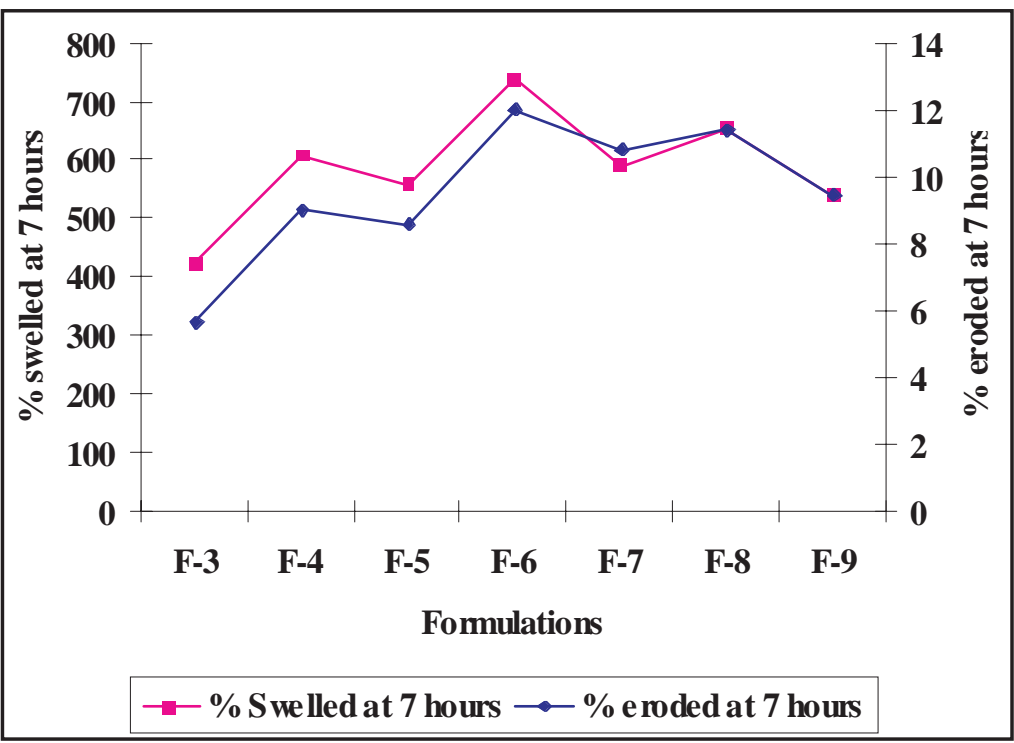

Fig. 3. Comparison of swelling and erosion index (at 7 hours) of different formulations of hydrophilic polymer based matrix tablets 
Between F-3 (contained 21.622\% CMC 50,000 cps) and F-4 (contained 43.243\% CMC 50,000 cps), F-4 showed more swelling and erosion index than F-3. The same result was observed for F-5 (contained 21.622\% methocel K15M CR) and F-6 (contained 43.243\% methocel K15M CR). From the observation it is clear that with increasing hydrophilic polymer concentration, swelling index were increased. Swelling and erosion index of F-5 and F-6 were more than that of F-3 and F-4. Methocel K 15M CR is a hydrophilic polymer with higher viscosity and control release grade. So, the swelling and eroding property of this polymer was found to be more than CMC 50,000 cps. Among all of the formulations F-6 showed highest swelling index (740.55\%) as well as erosion index $(12.017 \%)$ at 7 hours. In case of combined polymer containing formulations, F-8 showed more swelling index (652.439\%) and erosion index (11.351\%) than F-7 and F-9 (Fig. 3).

From the dissolution study it was observed that the release rate of aceclofenac in first two hours in acid media was so negligible (less than 1\%), that's why the result was not shown in the release curve (Figure 4). At this $\mathrm{pH}$, aceclofenac exists in its acidic form which is well known to be practically insoluble in the stomach (Sheu et al., 1992). When the dissolution was changed to $\mathrm{pH} 6.8$ phosphate buffer media, the drug release rate was slightly increased, possibly because the aceclofenac was partially converted to aceclofenac salt which is soluble (Yesmin et al., 2008). In pH
6.8 phosphate buffer media, F-1 (contained 21.622\% HPMC K100 cps) and F-2 (contained 43.243\% HPMC L100 cps) released about more than 65\% drug at 1 hour. So, it can be said that HPMC K100 cps had not so much sustained action at those concentrations. F-3 and F-4 contained 21.622\% and 43.243\% CMC 50,000 cps respectively and released about $68.705 \%$ and $45.901 \%$ drug at the end of 8 hours. CMC 50,000 cps had the capability to retard the release of aceclofenac upto 8 hours. Again, F-5 and F-6 (having 21.622\% and $43.243 \%$ methocel K15M CR) showed the release of $30.350 \%$ and $34.491 \%$ drug at 8 hours. Among the three types of hydrophilic polymers, methocel K15M CR was found to be more rate retarding than the other two. By increasing the concentration of polymers, release rate of drug were found to be decreased. F-7 to F-9 were prepared using combined hydrophilic polymers. F-7 (contained 21.622\% CMC 50,000 cps and same percent of methocel K15M CR) released 33.791\%, F-8 (contained 13.514\% CMC 50,000 cps and 29.729\% methocel K 15M CR) released 29.070\% and F-9 (contained 29.729\% CMC 50,000 cps and 13.514\% methocel K 15M CR) released 40.021\% aceclofenac at 8 hours. Among the combined polymer containing formulations, F-8 was found to be more rate retarding than F-7 and F-9 as it contained higher concentration of methocel K15M CR, which was found to be more sustaining one.

The dissolution data were used to calculate repeated measures ANOVA and post hoc test using SPSS software (version

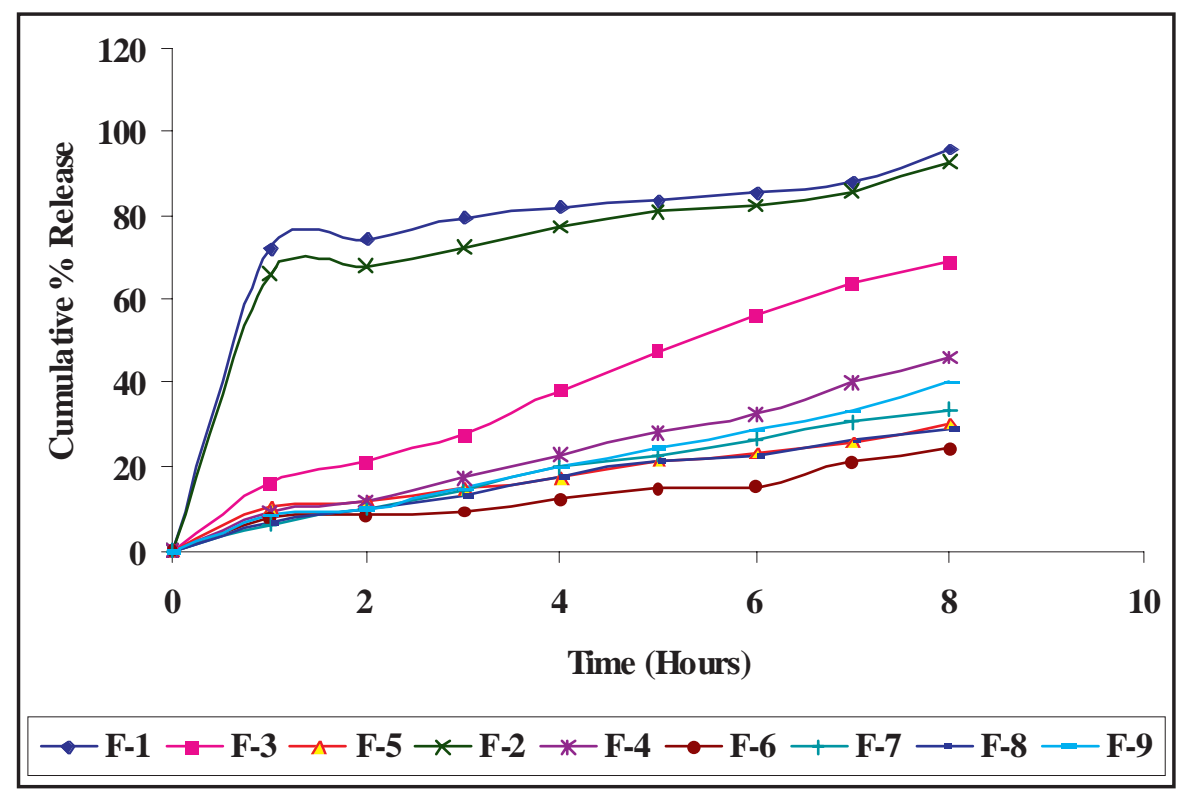

Fig. 4. Zero order release kinetics of different formulations of hydrophilic polymer based matrix tablets 
16.0). The within subject effect showed calculated $\mathrm{F}=$ $2.509 \times 10^{6}$ for all methods p value $=0.000$. So, time is highly significant at any reasonable level of significance. Thus it can be concluded that the percent release on time differed significantly. The multiple comparisons (Bonferroni and Dunnett) were also carried out. Dunett t tests treat one group as a control and compare all other groups against it. The paired comparison of the six groups with the control group give $\mathrm{p}$ value $=0.001$, whereas the comparison among F-5, F- value of 0.839 and 0.708 respectively. These values werewithin 0.45 to 0.89 , indicating the release mechanism from F-7 and F-8 were anomalous or non-Fickian or coupling of diffusion and erosion controlled. Only F-5 showed highest fitting with Higuchi model $\left(\mathrm{R}^{2}=0.969\right)$, indicating the release mechanism of aceclofenac from F-5 is mainly diffusion through porous matrix (Higuchi, 1963). Diffusion is related to transport of drug from the dosage matrix. As gradient varies, the drug is released, and the distance for

Table IV. Kinetic data obtained from various plot and $f_{2}$ values.

\begin{tabular}{|c|c|c|c|c|c|c|c|c|c|}
\hline \multirow[t]{2}{*}{ Formulation } & \multicolumn{2}{|c|}{ Zero order } & \multicolumn{2}{|c|}{ Higuchi } & \multicolumn{3}{|c|}{ Korsmeyer } & \multirow[t]{2}{*}{ MDT } & \multirow[b]{2}{*}{$f_{2}$} \\
\hline & $\mathrm{K}_{\mathrm{o}}$ & $\mathrm{R}^{2}$ & $\mathrm{~K}_{\mathrm{H}}$ & $\mathrm{R}^{2}$ & $\mathrm{R}^{2}$ & $\mathrm{~K}_{\mathrm{k}}$ & $n$ & & \\
\hline F-1 & 15.156 & -0.221 & 38.205 & 0.663 & 0.894 & 0.699 & 0.122 & 2.064 & 30.306 \\
\hline F-2 & 14.551 & -0.040 & 36.487 & 0.749 & 0.919 & 0.629 & 0.159 & 2.525 & 31.218 \\
\hline F-3 & 9.154 & 0.980 & 21.625 & 0.920 & 0.970 & 0.141 & 0.745 & 5.897 & 42.056 \\
\hline F-4 & 5.691 & 0.990 & 13.350 & 0.885 & 0.962 & 0.080 & 0.792 & 10.725 & 60.509 \\
\hline F-5 & 4.017 & 0.890 & 9.639 & 0.969 & 0.944 & 0.091 & 0.525 & 33.057 & 75.617 \\
\hline F-6 & 3.002 & 0.910 & 7.133 & 0.895 & 0.851 & 0.064 & 0.542 & 55.401 & REF \\
\hline F-7 & 4.458 & 0.988 & 10.513 & 0.918 & 0.996 & 0.059 & 0.839 & 13.238 & 68.706 \\
\hline F-8 & 3.917 & 0.961 & 9.311 & 0.949 & 0.985 & 0.065 & 0.708 & 19.560 & 77.066 \\
\hline F-9 & 4.917 & 0.990 & 11.540 & 0.888 & 0.960 & 0.068 & 0.799 & 12.746 & 65.704 \\
\hline
\end{tabular}

7 and F-8 gives p value $=1.0$, meaning the release profile of F-5, F-7 and F-8 measured at different time points are very much similar to that of the control group. Finally it can be stated that there was significant difference between the release patterns of aceclofenac from F-1 to F-6 and F-9 (p< $0.05)$. While determining similarity factor, $f_{2}$, the dissolution data of F-6 was considered as reference standard and that of F-4 to F-5 and F-7 to F-9 formulations were found to be more similar to F-6 as their value were within 50-100 (Table IV). This is according to the result obtained from ANOVA.

The data were treated with zero order, Higuchi and Korsmeyer model to interpret the release mechanisms from different formulations of tablets. The results were shown in Table IV. From Table IV, it was shown that release kinetics of most of the formulation were fitted to zero order (F-3, F4, F-6 and F-9) and Korsmeyer model (F-1, F-2, F-7 and F8) with regression coefficient of 0.910 to 990 (for zero order) and 0.894 to 0.996 (for Korsmeyer) respectively. So, it can be predicted that the release of aceclofenac from F-3, F-4, F6 and F-9 is independent of the concentration of drug in depot. F-1 and F-2 showed quick release of aceclofenac within 1 hour (which can be justified by observing their rate constant value). F-7 and F-8 had the release exponent (n) diffusion increases. This could explain why the drug diffuses at a comparatively slower rate as the distance for diffusion increases, which is referred as square-root kinetics or Higuchi's kinetics (Korsmeyer et al., 1983).

MDT is used to characterize the drug release rate from the dosage form and the retarding efficacy of the polymer. A higher MDT indicates a higher drug-retarding ability of the polymer and vice versa. The MDT value was found to be a function of polymer loading and viscosity grade of polymer. Table IV showed that MDT value was highest for F-6 (55.401 hours), then for F-5 (33.057 hours) and for F-8 (19.560 hours). Increasing the polymer concentration, the MDT's were found to be increased for these nine formulations. These observations are similar to the reported (Reza et al., 2003).

\section{Conclusion}

The matrix tablets were prepared successfully using hydrophilic polymers. It can be concluded that with some rare exception, swelling and erosion index were increased with the increasing hydrophilicity as well as the viscosity grade of the polymer. Thus the hydrophilic polymer based 
matrix tablets might release drug more slowly. A very viscous gel layer was formed around the matrix tablet and prevented the release of drug from depot. For that reason, their release rate constants were decreased and their MDT values were found to be increased.

\section{References}

Alderman D. A. (1984) A review of cellulose ethers in hydrophillic matrices for oral controlled-release dosage forms. Int. J. Pharm. Tech. Prod. Mfr. 5: 1-9.

Al-Taani B. M. and Tashtoush B. M. (2003) Effect of microenvironment $\mathrm{pH}$ of swellable and erodable buffered matrices on the release characteristics of diclofenac sodium. AAPS PharmSciTech. 4 (3): Article 43.

CDER. Center for Drug Evaluation and Research, Guidance for Industry, Dissolution Testing of Immediate Release Solid Oral Dosage, 1997. Available at: http://www.fda.gov/cder/Guidance/1713bp1.pdf. Accessed: September 19, 2006.

Donbrow M. and Samuelov Y. (1980) Zero order drug delivery from double-layered porous films: release rate profiles from ethylcellulose, hydroxypropylcellulose and polyethylene glycol mixtures. J. Pharm. Pharmacol. 32: $463-470$.

Dow Chemical Company. Using methocel cellulose ethers for controlled release of drugs in hydrophillic matrix systems. Available at: http://www.dow.com/ PublishedLiterature/dh_01e7/09002f13801e718c. pdf? filepath=methocel/pdf s/noreg / 198 02075.pdf\&fromPage=GetDoc. Accessed: August 24, 2006.

Durig, T. V. Enkatesh G. M. and Fassihi R. ( 1999) An investigation into the erosion behavior of high drug-load (85\%) particulate system de-signed for an extendedrelease matrix tablet: analysis of erosion kinetics in conjunction with variation in lubrication, porosity and compaction rate. J. Pharm. Pharmacol. 51: 1085-1092.

EMEA. European Agency for the Evaluation of Medicinal Products, Human Medicines Evaluation Unit, Note for Guidance on Quality of Modified Release Products: (A) Oral Dosage Forms; (B) Transdermal Dosage Forms; Section I (Quality), CPMP/QWP/604/96 (1999). Available at: http://www.emea.eu.int/ pdfs/human/qwp /060496en.pdf. Accessed: September 19, 2006.

Fell J. T. and Newton J. M. (1968) The tensile strength of lactose tablets. J. Pharm. Pharmacol. 20 (8):657-659.

Higuchi T. (1961) Rate of release of medicaments from ointment bases containing drugs in suspension. J. Pharm. Sci. 50: 874-875.

Higuchi T. (1963) Mechanism of sustained-action medication: theoretical analysis of rate of release of solid drugs dispersed in solid matrices. J. Pharm. Sci. 52: $1145-1149$.

Jacques C. H. M. and Hopfenberg, H. B. (1974) Stannett, V. Super case II transport of organic vapors in glassy polymers. In: Hopfenberger, H.B (ed.). Permeability of Plastic Films and Coatings to Gases, Vapors, and Liquids. (Plenum Press, New York) pp.73-86.

Korsmeyer R. W., Gurny R., Doelker E. M., Buri P. and Peppas N. A. (1983) Mechanism of solute release from porous hydrophilic polymers. Int. J. Pharm. 15: 25-35.

Krowczynsky L. (1987) Extended-Release Dosage Forms. (CRC Press, Boca Raton, FL).

Lee P. I. (1985) Kinetics of drug release from hydrogel matrices, J. Control. Release. 2: 277-288.

Mockel J. E. and Lippold B. C. (1993) Zero-order release from hydrocolloid matrices. Pharm Res. 10:10661070 .

Padmalatha D. K., Ranga Roa K.V., Baveja S., Fathi M. and Roth M. (1989) Zero-order release formulation of oxprenolol hydrochloride with swelling and erosion control. Pharm Res. 6: 313-317.

Parfitt K. (1999) Analgesics Anti-inflammatory and antipyretics. In Reynolds, J. E. F., (ed.) Martindale: The Complete Drug Reference, 32nd Ed., (Massachusetts), pp. 2-12.

Peppas N. A. (1985) Analysis of Fickian and non-Fickian drug release from polymers. Pharm Acta Helv. 60: 110-111.

Raghuram R. K., Srinivas M. and Srinivas R. (2003) Oncedaily sustained-release matrix tablets of nicorandil: for- 
mulation and in vitro evaluation. AAPS PharmSciTech. 4(4): Article 61.

Reynolds T. D., Dasbach T. P. Presented in AAPS 1999 New Orleans, Louisiana. A study of polymer blending and polymer erosion of different viscosity grades of hypormellose for hydrophilic matrix tablets. Dow chemical Company. Printed in 2002, USA. Accessed in 31 May 2009. Available at http://www.dow.com/ PublishedLiterature/dh_0035/0901b803800359ff.pdf?f ilepath=methocel/pdfs/noreg/198-02068.pdf\& fromPage $=$ GetDoc .

Reza M. S., Quadir M. A. and Haider S. S. (2003) Comparative evaluation of plastic, hydrophobic and hydrophilic polymers as matrices for controlled-release drug delivery. J. Pharm. Pharm. Sci. 6: 282-291.

Ruiz G. and Ghali E.S. (2006) Mucoadhesive delivery using caragreenan and eudragit RLPO. Revista De La Facultad De Cuimica Farmaceutica. 13(1): 31-39.
Sheu M., Chou H., Kao C., Liu C. and Sokoloski T. D. (1992) Dissolution of diclofenac sodium from matrix tablets. Int. J. Pharm. 85: 57-63.

Theeuwes F. (1983) Orososmotic system development. Drug Dev. Ind. Pharm. 9:1331-1357.

Wells J. E. and Aulton M. E. (1998) Preformulation. In: Aulton, M.E. (ed.). Pharmacutics: The Dosage Form Design. (Churchill Livingstone: Edinburgh). pp. 247248.

Yesmin F., Talukder M. M. U., Islam M. S., Laila S. and Haque T. (2008) Evaluation of aceclofenac loaded agarose beads prepared by ionotropic gelation method. S.J. Pharm. Sci. 1(1\&2): 10-17.

Received : June 28, 2009;

Accepted : Octorber 20, 2009 